\title{
Non-Naturalism and Reasons-Firstism: How to Solve the Discontinuity Problem by Reducing Two Queerness Worries to One
}

\author{
Victor Moberger ${ }^{1}$ (D)
}

Received: 22 January 2021 / Accepted: 12 September 2021 / Published online: 24 September 2021

(c) The Author(s) 2021

\begin{abstract}
A core tenet of metanormative non-naturalism is that genuine or robust normativity-i.e., the kind of normativity that is characteristic of moral requirements, and perhaps also of prudential, epistemic and even aesthetic requirements-is metaphysically special in a way that rules out naturalist analyses or reductions; on the nonnaturalist view, the normative is sui generis and metaphysically discontinuous with the natural (or descriptive or non-normative). Non-naturalists agree, however, that the normative is modally as well as explanatorily dependent on the natural. These two commitments - discontinuity and dependence - at least initially pull in opposite directions, and one of the central challenges to non-naturalism is how to reconcile them. In this paper I spell out the most pressing version of this discontinuity problem, as I propose to call it, and I go on to offer a novel solution. Drawing on the ideology of reasons-firstism, I formulate an account of normative explanation which reconciles the two commitments, and I argue that competing accounts either do not solve the problem or are implausible on independent grounds.
\end{abstract}

Keywords Non-naturalism · Discontinuity problem · Normative explanation · Reasons-firstism

\section{Introduction}

According to metanormative non-naturalists, the normative is sui generis and metaphysically discontinuous with the natural (or descriptive or non-normative). Non-naturalists agree, however, that the normative is modally as well as explanatorily dependent on the natural. These two commitments-discontinuity and

Victor Moberger

victor.moberger@philosophy.su.se

1 Department of Philosophy, Stockholm University, Stockholm, Sweden 
dependence - at least initially pull in opposite directions, and one of the central challenges to non-naturalism is how to reconcile them.

In this paper I spell out the most pressing version of this discontinuity problem, as I propose to call it, and I go on to offer a novel solution. Drawing on the ideology of reasons-firstism, I formulate an account of normative explanation which reconciles the two commitments, and I argue that competing accounts either do not solve the problem or are implausible on independent grounds.

I begin in Sect. 2 by explicating the discontinuity problem. In Sect. 3 I discuss and reject several previously proposed solutions. In Sect. 4 I present the reasonsfirstist solution and show how it evades the problems that beset extant proposals. In Sect. 5 I address a possible objection, and in Sect. 6 some concluding remarks are made.

\section{The Discontinuity Problem}

There are at least three distinct challenges to non-naturalism in the vicinity, associated with Mackie (1977), Jackson (1998) and McPherson (2012), respectively. I will distinguish between these challenges and argue that the Mackiean challenge is the most pressing of the three. This is because Jackson's and McPherson's challenges rely on certain precarious assumptions that the Mackiean challenge avoids. The upshot is that the discontinuity problem for non-naturalism is the problem of how to answer the Mackiean challenge. Or, at any rate, this is the problem that I will attempt to solve for non-naturalists.

I begin by explaining the non-naturalist view of normativity, which crucially informs all three challenges.

\subsection{Discontinuity}

A core tenet of non-naturalism is that genuine or robust normativity-i.e., the kind of normativity that is characteristic of moral requirements, and perhaps also of prudential, epistemic and even aesthetic requirements-is irreducible or sui generis. The underlying motivation is an intuition to the effect that this kind of normativity is special in a way that no naturalist analysis or reduction could hope to accommodate. ${ }^{1}$ Thus, according to David Enoch, "[n]ormative facts are just too different from natural ones to be a subset thereof" (2011: 4). Similarly, Michael Huemer writes that normative properties "are radically different from natural properties" (2005: 94; see also Dancy 2006: §7; FitzPatrick 2008: §7; and Parfit 2011: 326).

Importantly, this radical differentness or discontinuity is understood by non-naturalists in metaphysical terms. Thus, it applies not just to normative language and

\footnotetext{
1 This includes supernaturalist analyses or reductions. Throughout the paper, I use the term "natural" as a placeholder for the appropriate category. The Journal of Ethics does not use endnotes. Please shift all the endnotes to footnotes.
} 
thought, but also to normative properties or facts. These are held to be inherently different from natural properties or facts, independently of how they are represented.

The radical differentness of normative facts or properties rules out any sort of broadly speaking reductive relation to natural facts or properties. Thus, it rules out not just property identity, but also such relations as property composition, functional realization and the determinable-determinate relation. Without attempting to provide an exhaustive list of possible reductive relations, we can settle for a more intuitive gloss: As Enoch puts it, the non-naturalist view rules out that the normative is "nothing over and above" the natural (2011: 4). Call this non-naturalist view of normativity the discontinuity thesis. ${ }^{2}$

\subsection{Dependence}

Metaphysical discontinuity notwithstanding, non-naturalists agree that the normative depends on the natural at least in certain ways. First, everyone agrees that the normative supervenes on the natural, in the sense that there could not be a difference with respect to the normative without a difference with respect to the natural. The only controversy here concerns how the modality of this "could not" should be understood. Secondly, everyone agrees that the normative is, in some way or another, explained by the natural. When a particular act is wrong, for example, there must be something about the act which makes it wrong, such as causing pain or breaking a promise. Again, the only controversy here concerns how this "makes" should be understood.

Roughly put, the discontinuity problem for non-naturalism is how to reconcile this modal and explanatory dependence with the discontinuity thesis. I now turn to the three more specific challenges advertised above.

\subsection{Jackson}

A widely discussed challenge, put forward by Jackson (1998), relies on a particular criterion of property identity. According to this criterion, properties are identical just in case they are co-extensive as a matter of metaphysical necessity. In other words, no distinct properties are necessarily co-extensive. This criterion is one way of spelling out a Humean intuition (or suspicion) concerning "necessary connections between distinct existences." Assuming that normative properties supervene on natural properties with metaphysical necessity, the criterion implies that normative properties are themselves natural properties. This, in turn, rules out the nonnaturalist discontinuity thesis. ${ }^{3}$

Both premises of Jackson's challenge are controversial, however. First, it is controversial whether the normative supervenes on the natural with metaphysical

\footnotetext{
${ }^{2}$ For further discussion of how to understand the non-naturalist view of normativity, see Moberger (2019: §2.1; 2020: §II.1).

${ }^{3}$ This presentation of Jackson's argument is simplified. See Jackson (1998: 118-125) for the full version. Reconstructions of the argument are found in Majors (2005: §I), Enoch (2011: 137-138) and Bader (2017: §1).
} 
necessity. Although the claim that it does so may seem intuitively compelling, several recent critics have argued that the modality in question is more plausibly construed as weaker than metaphysical necessity (see, e.g., Hattiangadi 2018 and Roberts 2018). Also, the criterion of property identity that Jackson relies on is open to serious doubts, since properties are intuitively more fine-grained than the criterion allows. ${ }^{4}$ In any case, the criterion raises fundamental metaphysical questions about the nature of properties, which will hold Jackson's challenge hostage indefinitely. ${ }^{5}$

\subsection{McPherson}

In response to related worries, McPherson (2012) proposes a more modest way of spelling out the Humean intuition. Instead of ruling out metaphysically necessary connections between distinct properties, McPherson suggests that countenancing such connections merely comes at a price (albeit a hefty one), and only if the connections are taken to hold brutely between metaphysically discontinuous properties (as opposed to just numerically distinct ones). Still, if normative properties supervene on natural properties with metaphysical necessity, and if non-naturalists cannot explain why this connection holds, then the discontinuity thesis will commit them to a brute metaphysically necessary connection between discontinuous properties. And, according to McPherson, this counts significantly against their view. ${ }^{6}$

Again, McPherson's challenge might be countered by denying the requisite supervenience thesis. Furthermore, there is a crucial ambiguity in the Humean principle that McPherson relies on, and once we disambiguate it, the challenge either dissipates or remains inconclusive at best.

Suppose first that by "connections" we have in mind mere correlations. Perhaps metaphysically necessary correlations do call for explanation and thus could not plausibly be taken as brute. Understood this way, however, non-naturalists can easily evade the challenge by positing a metaphysically necessary explanatory relation between natural and normative properties. If normative properties obtain in virtue of natural properties, and necessarily so, then the supervenience correlation will no longer be brute. Furthermore, since the posited explanatory relation will not be a mere correlation, McPherson's challenge on the present interpretation gets no purchase on it.

But suppose instead that by "connections" we have in mind not just mere correlations, but relations in general. If so, the posited explanatory relation will fall under the scope of McPherson's challenge, and so the non-naturalist's easy response will

\footnotetext{
4 This point is argued in Majors (2005: §IV), Parfit (2011: 296-297) and Olson (2014: 93-94). See also Moberger (2020: §III.3), where I argue that basically the same critique applies also to Bader's (2017: §4) "hyperintensional analogue" of Jackson's criterion.

5 For example, Jackson's criterion does not sit well with a Platonic conception of the nature of properties. See Moberger (2020: §III) for discussion.

${ }^{6}$ See McPherson (2012: §3) for the full version. For discussion, see Moberger (2019).
} 
be rendered circular. ${ }^{7}$ However, on this interpretation McPherson's challenge is still less than compelling. Do metaphysically necessary relations between discontinuous properties always call out for explanation? It is hard to get an intuitive grip on this question. While I do think, as I will explain below, that a particular kind of brute relation between discontinuous properties is mysterious indeed, I'm not sure what to say about McPherson's more general claim. It's not that I have some particular reason to think that McPherson's principle on the current interpretation is false, but rather that I don't even know how to go about assessing it (short of quixotic piecemeal evaluation).

\subsection{Mackie}

The above worries do not refute Jackson's or McPherson's challenges, of course. Nevertheless, as I will explain shortly, it is an advantage of the Mackiean challenge that it avoids these worries.

Consider the famous "what in the world"-passage from Ethics: Inventing Right and Wrong:

What is the connection between the natural fact that an action is a piece of deliberate cruelty - say, causing pain just for fun - and the moral fact that it is wrong? It cannot be an entailment, a logical or semantic necessity. Yet it is not merely that the two features occur together. The wrongness must somehow be 'consequential' or 'supervenient'; it is wrong because it is a piece of deliberate cruelty. But just what in the world is signified by this 'because'? (Mackie 1977: 41)

The term "supervenient" notwithstanding, the relation that Mackie takes issue with here is not a mere correlation. As he puts it, "it is not merely that the two features occur together." Rather, his target is specifically an explanatory relation, signified by the "because" in phrases like "It is wrong because it is a piece of deliberate cruelty." Due to the discontinuity thesis, non-naturalists will have a hard time accounting for this relation. As Mackie notes, the relation "cannot be an entailment, a logical or semantic necessity." Nor can it be any other kind of broadly speaking reductive relation. Thus, it appears that non-naturalists will have to posit a metaphysically impenetrable, virtus dormitiva kind of explanatory relation. And, according to Mackie, commitment to such a "mysterious consequential link" (1977: 41) counts significantly against non-naturalism. ${ }^{8}$

Note that there is no mention of metaphysical necessity here. The point is not that non-naturalists are committed to a metaphysically necessary relation between

\footnotetext{
7 McPherson calls this "bruteness revenge" (2012: 223). Since he thus thinks his challenge applies also to putative explanatory relations, it would seem that he takes the term "connections" to cover more than mere correlations. However, his discussion of the "default combinatorial assumption" (McPherson 2019: §) suggests otherwise.

${ }^{8}$ The idea that a metaphysically explanatory relation between discontinuous facts or properties is queer is not a Mackiean idiosyncrasy, however. As Rydéhn (2019: §4.2.1) notes, in the literature on metaphysical grounding it is often implicitly assumed that the grounded entities are "nothing over and above" the grounding ones. Presumably this assumption is guided by something like the Mackiean aversion.
} 
discontinuous properties. Since the Mackiean challenge is thus not based on the Humean intuition concerning necessary connections between distinct existences, the challenge has the advantage of not relying on any controversial assumption about the supervenience of the normative on the natural being metaphysically necessary. Indeed, if anything the requisite metaphysically explanatory relation would appear even more mysterious if construed as metaphysically contingent, since we would then have the additional mystery of how a mere change of modal location could disrupt its mechanics.

Also, the Mackiean challenge does not rely on any particular criterion of property identity. Rather, the puzzle is how there could be metaphysically explanatory relations between discontinuous facts or properties: How could the fact that an action causes pain make it the case that the action is wrong, if causing pain and being wrong are radically different kinds of properties? The intuition here is analogous to the one animating the so-called hard problem of consciousness (Chalmers 1996; cf. McGinn 1989): How could biochemical processes in the brain give rise to phenomenal states such as being in pain or experiencing color, when phenomenal and biochemical properties seem so utterly different? By contrast, it is easy to get an intuitive sense of how being scarlet can make an object red, for example, or how certain physical properties can make an organism healthy. Such broadly speaking reductive explanatory relations appear intuitively accessible in a way that the non-naturalist's because-relation does not. Hence Mackie's question: Just what in the world is this queer because-relation? By thus relying on a more specific metaphysical intuition, the Mackiean challenge avoids the intuitive nebulosity of McPherson's challenge.

In response to the Mackiean challenge, non-naturalists can either concede a loss of plausibility points, or they can try to explain how they are not in fact committed to any metaphysically queer explanatory relation. In Sect. 4 I will pursue the latter strategy. I will argue that by placing a sui generis reason-relation at the bottom of the normative hierarchy, non-naturalists can successfully answer the Mackiean challenge. The point is not that non-naturalists will be rid of queerness worries, however, since a sui generis reason-relation is certainly queer by Mackiean lights. The point is rather that the explanatory connection between the normative and the natural will not involve any additional queerness, and so two worries will be reduced to one.

Before presenting this reasons-firstist solution to the discontinuity problem, however, I will consider competing accounts of normative explanation.

\section{Extant Proposals}

Various accounts of how non-naturalists should construe the metaphysics of normative explanation have been proposed in the literature. ${ }^{9}$ While the accounts may or may not have been proposed in order to deal with the discontinuity problem, I will consider them in that light. I will argue that they either fail to alleviate the Mackiean worry or are implausible on independent grounds.

\footnotetext{
${ }^{9}$ For an overview, see Fogal and Risberg (2020).
} 
Establishing that none of these accounts can solve the discontinuity problem is a tall order, of course, so let me make some qualifications. First, even if my arguments in this section should turn out to be less than conclusive, they might still put significant pressure on competing accounts, thus generating motivation and support for the reasons-firstist solution to be explored in Sect. 4. Second, even if my arguments against competing accounts should fail completely, it will still be interesting to see whether the reasons-firstist approach can (also) solve the discontinuity problem, since, if it couldn't, then this would count against it.

\subsection{The Simple Account}

On a straightforward account, particular natural facts fully metaphysically explain particular sui generis normative facts. ${ }^{10}$ Assuming a simple version of utilitarianism for illustration, we get the following picture (where " $\varphi$ " denotes a particular action and the arrow denotes full metaphysical explanation):

$\varphi$ is right

$\varphi$ maximizes happiness

Thus, on this account the particular natural facts are explanatorily sufficient with respect to the particular sui generis normative facts, and so normative principles do no metaphysical work in terms of explaining particular normative facts. Instead, normative principles are mere generalizations, summarizing the explanatory work that the particular natural facts do all on their own. Thus, normative principles are not part of the explanans, and the explanatory relations between the particular facts do not themselves have further explanations in terms of principles. ${ }^{11}$

The Simple Account clearly does not help address the discontinuity problem. If anything the account serves to illustrate and underscore the Mackiean worry: How could particular natural facts fully metaphysically explain particular sui generis normative facts, when the two are utterly different?

\footnotetext{
${ }^{10}$ I intentionally speak in term of metaphysical explanation rather than grounding here, since the notion of grounding is highly theorized and might come with some unwanted baggage. For example, grounding is usually taken to imply metaphysical necessitation, whereas the Mackiean challenge as I have construed it leaves the modal strength of the explanatory relation open. Also, my use of the term "explanation" is not intended to prejudge the debate between "unionism" and "separatism" concerning the relation between grounding and explanation. For an overview of the debate on metaphysical grounding, see Bliss and Trogdon (2016).

${ }^{11}$ The simple account is advocated by Selim Berker, who suggests that the mere-generalization view "is the traditional way of understanding the content of moral principles" (2019: 929).
} 


\subsection{Principled Accounts}

The problem with the Simple Account from a Mackiean point of view is that it leaves the metaphysical chasm between the natural and the sui generis normative unaddressed. There are however accounts that try to tackle the issue by having normative principles do metaphysical work. These accounts come in two different versions. Following Berker (2019), we can call them Principles as Partial Explanans and Principles as Meta-Explanans, respectively. According to Principles as Partial Explanans, normative principles together with particular natural facts fully explain particular normative facts:

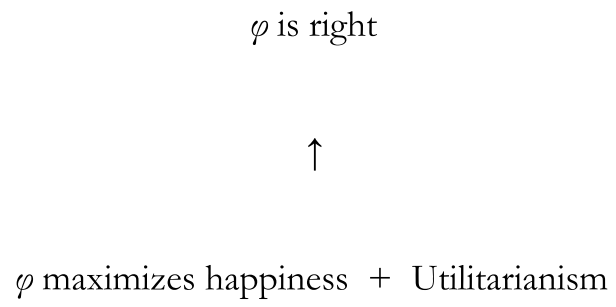

On this account normative principles thus stand in a relation of partial explanation to particular normative facts. ${ }^{12}$

According to Principles as Meta-Explanans, normative principles are not part of the explanans with respect to particular normative facts. Instead they figure in the background:

$\varphi$ is right

$\uparrow \leftarrow$ Utilitarianism

$\varphi$ maximizes happiness

On this account, normative principles thus fully explain why certain particular natural facts fully explain certain particular normative facts. ${ }^{13}$

In either case it would appear that the Mackiean worry is alleviated: on Principles as Partial Explanans, the gap between explanans and explanandum is closed by building sui generis normative content into the explanans; and on Principles as Meta-Explanans, the gap remains but is bridged by means of normative principles.

Although it may thus appear that the discontinuity problem is solved, this appearance is deceptive. The basic problem is this: once we spell out the form of the

12 Principles as Partial Explanans is assumed by Rosen (2017).

13 Principles as Meta-Explanans is advocated by Bader (2017). 
normative principles, then either the Mackiean worry reappears or even worse trouble ensues. Or so I will argue.

\subsection{Against Principled Accounts}

My strategy is as follows: I will consider four different accounts of how normative principles should be understood more precisely, and I will argue that none of these accounts manages to solve the discontinuity problem. This conclusion is independent of whether normative principles are plugged into Principles as Partial Explanans or Principles as Meta-Explanans. ${ }^{14}$ Since I don't know of any other promising way of spelling out the form of normative principles, I tentatively conclude that appealing to normative principles will not solve the discontinuity problem.

\subsubsection{Generalizationism}

According to one proposal, normative principles should be understood as universal generalizations (Rosen 2017). Thus, using again a simple version of utilitarianism for illustration, moral principles will have the following form (where the appropriate modal strength of the necessity operator will depend on the modal strength of normative supervenience):

Necessarily, for all actions $x, x$ is right iff and because $x$ maximizes happiness.

Invoking such principles does nothing to alleviate the Mackiean worry, however. This is perhaps easiest to see assuming Principles as Meta-Explanans, in which case the generalization merely states that the mysterious consequential links obtain:

$$
\begin{aligned}
& \varphi \text { is right } \\
& \uparrow \leftarrow \text { Necessarily, for all actions } x, x \text { is right iff } \\
& \text { and fully because } x \text { maximizes happiness }
\end{aligned}
$$

$\varphi$ maximizes happiness

A mere statement about happiness-maximizing facts playing the requisite explanatory role does not demystify that role, and so the Mackiean worry remains (cf. Glazier 2016: $\S 5$ and Fogal and Risberg 2020: §4).

Assuming instead Principles as Partial Explanans, the generalization will state that a relation of partial explanation obtains between the particular facts:

\footnotetext{
${ }^{14}$ For more specific critiques of each account, see Berker (2019). For a more specific critique of Principles as Partial Explanans, see Bader (2017: 117).
} 
$\varphi$ is right

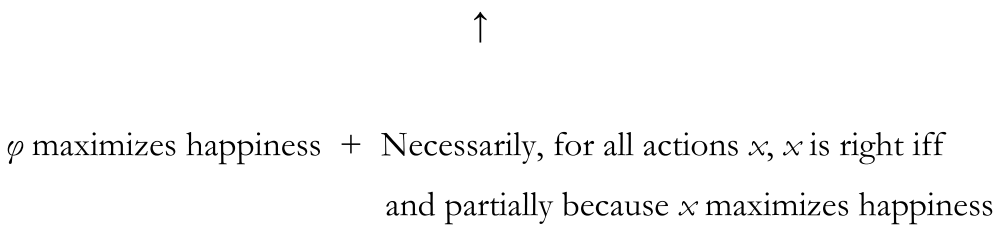

This also does nothing to demystify the issue. If it was mysterious how particular happiness-maximizing facts could be explanatorily sufficient with respect to particular rightness-facts, then adding a mere statement about their partial explanatory role does not fill out the explanans in a way which makes it any easier to see how it could be explanatorily sufficient. (The principle could not, of course, state that the happiness-maximizing facts are explanatorily sufficient on their own, since that would be to abandon Principles as Partial Explanans. But even if it could, a mere statement about their explanatory sufficiency would not help.) Again, the Mackiean worry remains. $^{15}$

\subsubsection{Essentialism}

The basic problem with generalizationism is that generalizations are mere statements about the explanatory role of the particular natural facts. What is needed is rather something that explains why the generalizations themselves hold.

According to one influential idea, metaphysical explanation bottoms out with facts about essence; that is, with facts about the nature of some suitable entity (see, e.g., Rosen 2010 and Dasgupta 2014). Perhaps the essence of something in the vicinity can bridge the gap between the natural and the sui generis normative, thus rendering the explanatory relation between the particular facts non-mysterious. If so, essentialism will give us the following picture (assuming Principles as Meta-Explanans):

15 This point touches upon more general problems for Principles as Partial Explanans. See Berker (2019: $\S \S 3-5)$ for discussion. 
$\varphi$ is right

$\uparrow \leftarrow$ It lies in the nature of $A$ that, necessarily,
for all actions $x, x$ is right iff and fully
because $x$ maximizes happiness

$\varphi$ maximizes happiness

What might $A$ be? One suggestion is that it lies in the nature of the sui generis normative properties that their instantiation is explained by the instantiation of the relevant natural properties (Enoch 2011: 147-148). Another possibility is that it lies in the nature of the relevant natural properties that their instantiation explains the instantiation of the sui generis normative properties. And there are other possibilities as well. ${ }^{16}$

Unlike generalizationism, essentialism does not render the principles explanatorily inert. The principles will not be mere statements about the explanatory role of the particular natural facts, but rather statements about something distinct from that role which could potentially explain it.

However, even if otherwise unproblematic, from a Mackiean point of view essentialism will merely relocate the discontinuity problem. If it was mysterious how the particular natural facts could explain the particular sui generis normative facts, then the appeal to essence will just move the bump in the carpet. Now we have an equally mysterious essence on our hands instead.

It might be helpful here to consider an analogy (or parody). Suppose we are impressed by the hard problem of consciousness, finding it mysterious how, in the words of Colin McGinn, "technicolour phenomenology [could] arise from soggy grey matter" (1989: 349). If so, we are not going to find it very illuminating to be told, for example, that it lies in the nature of certain functional states of that soggy matter to give rise to certain conscious states. That would merely invite a rephrasing of the issue in terms of how there could be such functional states. Similarly, appealing to essence in the present case would merely invite a rephrasing of the Mackiean worry. As I explained above, the problem that Mackie sees with respect to non-naturalism and normative explanation is precisely the intuitive impenetrability of the supposed explanatory link. In this respect the discontinuity problem for

\footnotetext{
16 As Leary (2017: §4) points out, there is an issue about how to reconcile essentialism with the nonnaturalist's discontinuity thesis. Building explanatory connections between natural and sui generis normative properties into the nature of either kind of property would appear to force too much metaphysical intimacy between them. Leary's own suggestion is that non-naturalists posit an intermediate layer of "hybrid properties," which are neither natural nor sui generis normative. I will not pursue this issue here, however. For critique of Leary's proposal, see Faraci (2017) and Toppinen (2018).
} 
non-naturalism is analogous to the hard problem of consciousness. And the appeal to essence is equally ineffectual. ${ }^{17}$

Note that the point here is not that there is some general problem with appealing to essences for metaphysically explanatory purposes. For example, it may well be that essences underwrite the explanatory hierarchy of the physical world, as suggested by Dasgupta (2014). In that case we are dealing with explanatory links between metaphysically continuous facts and properties, and so those links are not mysterious to begin with. On the contrary, it seems rather easy to get an intuitive grip on how physical facts could explain chemical facts, for example. But insofar as a supposed explanatory link is metaphysically opaque, the appeal to essence will merely serve to further encapsulate that opacity.

Note also that the objection here is not identical to the one that McPherson labels "bruteness revenge" (2012: 223). The point is not that the essentialist, in order to explain a metaphysically necessary supervenience connection between discontinuous properties, will ultimately end up positing another metaphysically necessary connection between discontinuous properties. As I explained earlier, the Mackiean critique does not hinge on normative supervenience being metaphysically necessary. Indeed, the supervenience correlation between the normative and the natural is not the focal point of Mackie's objection in the first place. Rather, the issue is how there could be a metaphysically explanatory connection between discontinuous properties, regardless of whether the connection is taken to be metaphysically necessary.

\subsubsection{Nomologism}

Much the same considerations apply to a different proposal, which substitutes metaphysical laws for essences:

\footnotetext{
${ }^{17}$ It might be objected that the analogy with the hard problem of consciousness in fact serves to undermine the Mackiean worry, since the hard problem obviously should not make us doubt for a moment that we are conscious. Why, then, should the discontinuity problem make us doubt that sui generis normative properties are instantiated? The answer is that in the case of consciousness there are countervailing reasons, which massively outweigh the prima facie case provided by the hard problem. The same may also be true in the normative case, at least as far as the present paper is concerned. The point is merely that the discontinuity problem, unless solved, puts significant pressure on non-naturalism.
} 


$$
\begin{aligned}
& \varphi \text { is right } \\
& \uparrow \leftarrow \text { It is a metaphysical law that, necessarily, } \\
& \text { for all actions } x, x \text { is right iff and fully } \\
& \text { because } x \text { maximizes happiness }
\end{aligned}
$$

$\varphi$ maximizes happiness

As I understand the notion of a metaphysical law here, laws unlike essences are not taken to inhere in entities such as properties or objects. The fact that a metaphysical law obtains is not a fact about some such entity. Instead, the laws are just supposed to be out there in the world, as it were, regulating its metaphysical behavior.

Importantly, laws are not mere universal generalizations. Thus, in the present case the normative law would not be a mere summary of the explanatory connections between the particular natural and sui generis normative facts throughout the relevant modal universe. Rather, the law would itself constitute some sort of general explanatory connection, which is distinct from and underwrites the particular ones. ${ }^{18}$

I think it is rather straightforward to see that the problem with mystery encapsulation arises here as well. The Mackiean concern would just have to be rephrased as the issue of how there could be such a law. Again, the point is not that there is some general problem with positing metaphysical laws for explanatory purposes. Nor is it that the law would have to be a brute metaphysically necessary connection between discontinuous properties. Instead, the problem is that one mysterious consequential link has been traded for another.

\subsubsection{Dualism}

If neither generalizations, essences nor laws can help non-naturalists, then what remains? I will end this section by considering an ingenious, but ultimately unsuccessful proposal made by Knut Olav Skarsaune (2015).

Skarsaune suggests that non-naturalists distinguish between two different kinds of normative properties: those that apply to ordinary objects of assessment, such as actions, mental states and societal arrangements; and those that apply to the abstract types of which these ordinary objects of assessment are tokens. ${ }^{19}$ Assuming a simple version of utilitarianism for illustration, a particular action which maximizes happiness would then have the token-applying normative property of being right ${ }_{\text {TOKEN }}$,

\footnotetext{
18 There is an issue, however, about how to express such a general explanatory connection in natural language. See Glazier (2016: §5) for discussion. See also Berker (2019: §8) and Fogal and Risberg (2020: $\S 5)$.

${ }^{19}$ Skarsaune calls his proposal "moral platonism," due to its commitment to abstract objects such as types.
} 
whereas the action-type maximizing happiness would have the type-applying normative property of being right ${ }_{\mathrm{TYPE}}$.

What is the relation between these dual kinds of normative properties? Skarsaune suggests that the type-applying properties are fundamental, and that the token-applying properties should be understood in terms of them. More specifically, whenever a particular action $\varphi$ is right ${ }_{\text {TOKEN }}$, then this consists in $\varphi$ being a token of a right ${ }_{\mathrm{TYPE}}$ action-type. Assuming utilitarianism, a particular action $\varphi$ being right ${ }_{\text {TOKEN }}$ consists in $\varphi$ being a token of the right ${ }_{\mathrm{TYPE}}$ action-type maximizing happiness.

Skarsaune's account thus gives us the following picture of normative explanation (assuming Principles as Partial Explanans):

$$
\varphi \text { is right } \text { TOKEN }_{\text {Th }}
$$

$$
\begin{array}{r}
\uparrow \\
\varphi \text { maximizes happiness }+ \text { The action-type maximizing } \\
\text { bappiness is right }{ }_{\mathrm{TYPE}}
\end{array}
$$

In the background, or perhaps inserted into the explanans, is the property identity:

being right TOKЕN $_{\text {being a token of a right }}$ $_{\text {TYPE }}$ action-type

Unlike the previous accounts, Skarsaune's account does indeed promise demystification. It is not hard to see how the fact that $\varphi$ maximizes happiness and the fact that maximizing happiness is right ${ }_{\mathrm{TYPE}}$ could together metaphysically explain the fact that $\varphi$ is a token of a right ${ }_{\text {TYPE }}$ action-type. And, according to the account, the latter is just what it is for $\varphi$ to be right TOKEN .

One might of course have general qualms about countenancing abstract objects such as action-types, and one might also be skeptical about there being highly umbrellalike action-types such as maximizing happiness. I will set such worries aside, however. ${ }^{20}$ Instead, I will focus on a more basic problem with Skarsaune's account.

\footnotetext{
${ }^{20}$ Mackie briefly anticipates a dualist solution to the discontinuity problem. He says that "if there were objective values they would presumably belong to kinds of things or actions or states of affairs," and he goes on to say that non-naturalists might attempt to solve the discontinuity problem by claiming that "wrongness is a higher order property belonging to certain natural properties" $(1977: 23,41)$. His response consists in asking: "[B]ut what is this belonging of properties to other properties, and how can we discern it?" (1977: 41) It is hard to know what to make of this response, however. At face value Mackie seems skeptical about the possibility of properties having properties (and about our ability to know about it). But it seems rather straightforward how properties could have properties. For example, the property of being red has the property of being a color property, and the property of being a cat has the property of being an abstract object. Perhaps Mackie is just generally skeptical about the existence of abstract objects, but as I mentioned in the text I will set such worries aside.
} 
On Skarsaune's account, normative principles are claims about action-types having type-applying normative properties. But this flies in the face of the most basic concern of normative ethics, namely to give systematic accounts of what is ultimately important, or what ultimately matters. Intuitively, it is the particular objects of assessment that matter, not the types of which they are tokens. For example, while tokens of torture are appalling, the action-type itself appears completely indifferent. It just sits there in the abstract realm, as it were, together with sets, numbers and propositions. As long as it is never tokened, everything is just fine.

This intuitive indifference of action-types leads to two more specific problems. First, since the token-applying normative properties do make a difference, it is not plausible to suppose that they could be understood in terms of the intuitively indifferent type-applying ones. For example, it is not plausible to suppose that the horror of particular acts of torture, reflected in wrongness ${ }_{\text {TOKЕN }}$, could be accounted for in terms of the intuitively inert wrongness ${ }_{\mathrm{TYPE}}$. It matters, of course, that a particular act is a token of the action-type torture, but the point is that this mattering cannot plausibly be accounted for in terms of the independent and prior mattering of the action-type. Rather, insofar as the action-type can be said to matter at all, this has be derivative of the independent and prior normative status of its tokens. Put another way, the action-type torture could only have a normative status via the suffering inflicted by its tokens, which makes them wrong, where this in turn could be said to make the action-type derivatively wrong.

Second, because action-types seem indifferent, it is not clear how Skarsaune's type-applying properties are even normative properties to begin with. For example, any property worth calling wrongness should reflect badly on its bearer. But wrongness $_{\text {TYPE }}$ wouldn't reflect badly on its bearer, and so it is hard to see how wrongness $_{\text {TYPE }}$ is a kind of wrongness in the first place. Indeed, I have a hard time understanding what it even means to say that an abstract object has a normative property, if this is not just a convenient way of talking about its actual or possible instances. (We often talk that way, saying perhaps that a certain type of organism has four legs and a tail. No abstract object has four legs and a tail, however.)

As clever as it is, I conclude that Skarsaune's dualist account fails. While it promises to demystify the explanatory relation between the natural and the sui generis normative, at bottom the account just doesn't seem to make sense.

This concludes my survey of competing accounts of normative explanation. In the next section I present the reasons-firstist account.

\section{How to Reduce Two Queerness Worries to One}

The upshot of Sect. 3 is twofold: First, the particular natural facts cannot be left to do the requisite metaphysical work all on their own, since that would leave the discontinuity problem unaddressed. Second, the problem cannot be solved by means of normative principles, at least not if these are understood in accordance with any of the four accounts discussed (generalizationism, essentialism, nomologism and dualism). 
In this section I will propose that non-naturalists adopt an account that has neither principles nor particular natural facts do any metaphysical work. Instead, the metaphysical work is done by particular facts about normative reasons. The proposal thus fits into the broader program of reasons-firstism in metaethics (see, e.g., Schroeder 2007 and Scanlon 2014).

I begin with a fairly standard explication of the notion of a normative reason. I then go on to explain how the notion can be employed to solve the discontinuity problem.

\subsection{Normative Reasons}

A normative reason is standardly taken to be a fact that favors (or supports or calls for) performing a certain action (or perhaps forming a certain attitude). For the fact to be a reason just is for the fact to stand in this relation of normative support to the action. Hence, the relation is sometimes referred to as the reason-relation. ${ }^{21}$

Typically, the reason will be a fact about the action in question. Assuming utilitarianism, for example, the fact that does the favoring is presumably the fact that the action maximizes happiness. Thus, using " $R$ " to signify the reason-relation, we get the following picture:

( $\varphi$ maximizes happiness) $\mathrm{R} \varphi$

Let us call complex facts of this kind "reason-facts." A reason-fact is thus a fact about a certain fact being a reason for a certain action.

Normative reasons can be contrasted with both deliberative reasons and motivating reasons. A deliberative reason is a proposition that the agent takes to be true and to normatively support the action in question. For example, my deliberative reason for giving to charity might be that it would maximize happiness. (Ideally, if it would indeed maximize happiness and if this does indeed favor the action, then my deliberative reason is also a normative reason.) Motivating reasons are psychological states which causally explain why agents act as they do. For example, perhaps I gave to charity because I wanted to maximize happiness and believed that giving to charity would do so.

Neither deliberative nor motivating reasons presuppose or are presupposed by normative reasons (at least not from a non-naturalist point of view). Thus, we might have deliberative reasons that do not correspond to normative reasons, and we might have beliefs and desires which causally explain our behavior even if our behavior enjoys no normative support. Conversely, certain actions might enjoy normative support even if we see nothing to support them and even if we are never motivated to perform them. Importantly, just as the normative reason-relation is not a causally

\footnotetext{
${ }^{21}$ Some reasons rather count against performing certain actions. I ignore this for simplicity. For ease of exposition I also construe the reason-relation as a two-place relation, holding between a particular fact and a particular action. One might want to include additional places, however, such as agent, circumstances and enablers.
} 
explanatory relation, it is not a metaphysically explanatory relation either. I will return to this point shortly.

\subsection{Reasons as Fundamental}

The central tenet of reasons-firstism is what Mark Schroeder calls "Reason Basicness," according to which "[w] hat it is to be normative, is to be analyzed in terms of reasons" (2007: 81). What this means is that the normativity of normative properties such as moral rightness and wrongness, duty and obligation, permissibility and impermissibility, etc., is to be understood in terms of reasons. Or, more properly speaking, the normativity of such properties should be understood in terms of the reason-relation, which constitutes the distinctly normative aspect of reasons themselves.

This picture leaves open whether the analysis in terms of the reason-relation is conceptual or metaphysical. It also leaves open whether the reason-relation itself can be further analyzed, allowing both non-naturalists and reductive naturalists like Schroeder to adopt reasons-firstism. According to non-naturalist reasons-firstists, the reason-relation is sui generis.

On reasons-firstism, then, the distinctly normative aspect of a property such as rightness can be analyzed in terms of reasons. Disregarding non-normative aspects of rightness for simplicity, we get the following property identity:

being pro tanto right $=$ being reason-supported.

With this property identity in the background, there should be no mystery about how the following could hold (again assuming utilitarianism):

$$
\varphi \text { is pro tanto right }
$$

$(\varphi$ maximizes happiness $) \mathrm{R} \varphi$

Assuming that the fact that $\varphi$ is pro tanto right just is the fact that $\varphi$ is reasonsupported (due to the above property identity), and since the fact that $\varphi$ is reasonsupported is non-mysteriously explained by the fact that $\varphi$ is supported by a specific reason (the fact that $\varphi$ maximizes happiness), there is nothing about the relation between explanans and explanandum for Mackie to take issue with. The explanatory move from reason-fact to rightness-fact is a rather straightforward intra-normative affair, and so explanans and explanandum are metaphysically continuous.

There is a further issue, of course, about how to get from pro tanto rightness to overall rightness. Also, other normative properties such as wrongness and permissibility need to be tethered to reasons as well. But working out these details is again an intra-normative affair, which does not invite specifically Mackiean worries. 
The idea, then, is that non-naturalist reasons-firstists can ground the whole normative domain in reason-facts, while leaving reason-facts themselves ungrounded. More precisely, while it will not be a brute fact that a particular action is normatively supported, it will be a brute fact that it is normatively supported by a certain fact about it. And if so, there will be no metaphysically explanatory relation between discontinuous facts or properties left in the picture.

The upshot, as I've said, is that two queerness worries are reduced to one. While non-naturalists will still be committed to "objective prescriptivity" (Mackie 1977, ch. 1), specifically in the form of a sui generis reason-relation, they will no longer be committed to a metaphysically explanatory relation between discontinuous facts or properties. As I mentioned earlier, the reason-relation is not an explanatory relation of any kind. ${ }^{22}$

\subsection{The Role of Principles}

If particular reason-facts are fundamental, then what role do normative principles play? Normative ethics, after all, is not merely interested in particular normative facts, but seeks systematic accounts in the form of normative principles.

To begin with, the proposed account will give us generalizations of reason-facts. Assuming utilitarianism for illustration once again, we get:

Necessarily, for all actions $x$, if $x$ maximizes happiness, then the fact that $x$ maximizes happiness favors $x$.

This principle will then give us:

Necessarily, for all actions $x$, if $x$ maximizes happiness, then $x$ is reason-supported.

And assuming the reasons-firstist identification of pro tanto rightness with reasonsupportedness, we get:

Necessarily, for all actions $x$, if $x$ maximizes happiness, then $x$ is pro tanto right.

Finally, assuming that we have worked out the intra-normative issue of how to get from pro tanto rightness to overall rightness (which utilitarianism makes easy), we get:

\footnotetext{
${ }^{22}$ Olson (2014: 98-99) similarly suggests that non-naturalists can reduce two queerness worries to one by assuming that certain natural properties have "further, relational [...] non-natural properties of being right-making, wrong-making, ought-making, etc." According to Olson, this would account for the modal and explanatory connection between the natural and the sui generis normative, but without involving any "additional cost to what non-naturalists are committed to already." I'm not sure what Olson precisely has in mind with right-making, wrong-making and ought-making, however. If these relations are supposed to be normative relations akin to the reason-relation, then Olson's proposal is congenial with mine. But if they are supposed to be metaphysically explanatory relations, then as far as I can tell the proposal would at best relocate the discontinuity problem.
} 
Necessarily, for all actions $x, x$ is right iff $x$ maximizes happiness.

The necessity operator can then be assigned a suitable modal strength, depending on the modal strength of normative supervenience.

The problem with this derivation is that the hyperintensionality of the reasonrelation gets lost in the process. To a utilitarian, instances of happiness-maximization have normative relevance in a way that instances of other properties do not, even if these other properties should turn out to be necessarily co-extensive with happiness-maximization. Suppose, for example, that happiness-maximization is necessarily co-extensive with divine commandedness. If so, the final utilitarian principle above will entail:

Necessarily, for all actions $x, x$ is right iff $x$ is divinely commanded.

Thus, the normative relevance of facts about happiness-maximization in particular is not reflected in the final utilitarian principle.

In order to secure the requisite hyperintensionality, we can define a distinct notion of normative explanation as follows (where the arrowhead denotes full normative explanation and, as before, the arrow denotes full metaphysical explanation $)^{23}$ :

$\varphi$ is reason-supported $\wedge$

$\varphi$ maximizes happiness $\varphi$ is reason-supported

$$
=
$$

( $\varphi$ maximizes happiness ) $\mathrm{R} \varphi$

We can now improve upon the above derivation, with "because" denoting normative explanation in the defined sense:

Necessarily, for all actions $x$, if $x$ maximizes happiness, then the fact that $x$ maximizes happiness favors $x$.

Necessarily, for all actions $x$, if $x$ maximizes happiness, then $x$ is reason-supported because $x$ maximizes happiness.

Necessarily, for all actions $x$, if $x$ maximizes happiness, then $x$ is pro tanto right because $x$ maximizes happiness.

Necessarily, for all actions $x, x$ is right iff and because $x$ maximizes happiness. This final principle will not entail:

Necessarily, for all actions $x, x$ is right iff and because $x$ is divinely commanded.

\footnotetext{
${ }^{23}$ Cf. Rosen’s (2017: §3) definition of "normative grounding" in terms of metaphysical grounding together with moral laws.
} 
Thus, the hyperintensionality of the reason-relation is preserved.

This process can then be repeated for other normative properties such as wrongness and permissibility. Assuming that the intra-normative promises of reasonsfirstism thus work out, the role of principles will be just as it should be: to give general and hyperintensional criteria for rightness, wrongness etc., which is the traditional role of principles in normative ethics. Importantly, there is no Mackiean worry attached to the "because" in these principles, as long as we bear in mind that it denotes normative explanation in the defined sense.

\section{An Objection}

In this section I respond to a possible objection, according to which the proposed reasons-firstist account leaves an explanatory deficit.

Suppose we have two particular actions, both of which maximize happiness. Assuming utilitarianism we thus have:

\section{( $\varphi$ maximizes happiness $) \mathrm{R} \varphi$}

\section{( $\psi$ maximizes happiness ) $\mathrm{R} \psi$}

According to the proposed account, reason-facts like these are fundamental, and so there is no metaphysical explanation for why they hold. But that might appear counterintuitive. Why is it indeed impossible, with whatever modal force is appropriate, for the actions to maximize happiness without this favoring the actions? Why, for example, couldn't one of the reason-facts hold but not the other? This is not explained by the principle:

Necessarily, for all actions $x$, if $x$ maximizes happiness, then the fact that $x$ maximizes happiness favors $x$.

This principle is a mere statement about the reason-facts in question obtaining throughout the relevant modal universe, and a mere statement to the effect that something obtains, even if true, does not explain why it obtains. What is needed is rather something that explains why the above principle holds. But reasons-firstists cannot accommodate this demand, and so we are left with an explanatory deficit. Or so the objection goes.

It isn't obvious to me that there is any deficit, however. While it seems intuitively clear that particular facts about rightness, wrongness and other monadic normative properties cannot be brute, it seems far from intuitively clear that particular reasonfacts cannot be brute. Berker (2019: 931) puts this point nicely:

Must [particular reason-facts] always obtain in virtue of other facts? That they might not seems very much to be a live theoretical option. While it is mystery mongering to hold that the wrongness of what I did last week is a brute fact that cannot be explained, it is not necessarily mystery mongering to hold that nothing explains why what it's like to be in agony is a reason for me to avoid future agony. [...] In short, it is only by focusing on an overly narrow diet of 
examples that it might seem as if all normative properties and relations must be resultant $[\ldots]$. [T] he reason relation is an excellent candidate for a nonresultant normative relation.

Arguably, then, reasons-firstists are right to take particular reason-facts as brute (cf. Scanlon 2014: 41-42).

I will not insist on this point, however. Instead, in the rest of this section I will argue that the objection can indeed be accommodated by appealing to what I will call reason-laws, and without abandoning what is important to reasons-firstism. To be fair, this will depend on how committed reasons-firstists are to particular reasonfacts being metaphysically fundamental. In any case, whether or not the proposal deserves to be called reasons-firstist, there is a way to shoulder the putative explanatory burden. And, importantly, by appealing to reason-laws it can be done without re-inviting the Mackiean worry.

A few paragraphs back, I said that the following principle does not explain what the objector wants explained:

Necessarily, for all actions $x$, if $x$ maximizes happiness, then the fact that $x$ maximizes happiness favors $x$.

But suppose we convert this principle into a metaphysical law:

It is a metaphysical law that, necessarily, for all actions $x$, if $x$ maximizes happiness, then the fact that $x$ maximizes happiness favors $x$.

This is not a mere statement about what goes on reasons-wise throughout the relevant modal universe. Rather, it is a statement about a distinct entity which could potentially accommodate the objection. Placing this reason-law at the bottom of the explanatory hierarchy, we get the following picture:

\author{
$\varphi$ is pro tanto right \\ ( $\varphi$ maximizes happiness $) \mathrm{R} \varphi$
}

It is a metaphysical law that, necessarily, for

all actions $x$, if $x$ maximizes happiness, then

the fact that $x$ maximizes happiness favors $x$ 
Unlike the appeal to metaphysical laws considered in Sect. 3.3.3 above, this explanatory picture does not simply relocate a mysterious consequential link between discontinuous facts. The explanatory steps are a wholly intra-normative affair, and the reason-law does not encapsulate any explanatory relation. Furthermore, although particular reason-facts will not be fundamental, they will at least be prior to other particular normative facts. And I take it that this is the most central tenet of reasons-firstism.

I am not claiming that non-naturalist reasons-firstists should adopt this proposal. The point is merely that if the present objection does indeed have force (and it is not clear that it does) then there is a way to accommodate it without simply gift-wrapping the discontinuity problem. Whether the proposal is in the end defensible will depend on more general metaphysical issues concerning the viability of appealing to metaphysical laws for explanatory purposes. Also, whether the proposal is available to reasons-firstist non-naturalists will depend on how committed they are to reasonfacts rather than reason-laws being first.

\section{Conclusion}

In this paper I have articulated what I take to be the most pressing version of the discontinuity problem for non-naturalism, and I have offered a reasons-firstist solution which improves upon extant proposals in several ways. The problem in its most pressing form is that non-naturalists, due to their view of the nature of normativity, appear to be committed to a mysterious explanatory link between discontinuous facts. The challenge is to explain why this is merely an appearance. This cannot be done by denying that the normative supervenes on the natural with metaphysical necessity, since the precise modal force of the explanatory link is not part of the concern. Also, the challenge cannot be met by having normative principles bridge the discontinuity gap, since that will at best relocate the mystery. Instead, non-naturalists should place particular reason-facts at the bottom of the normative hierarchy, allowing the "because" of normative explanation to be accounted for by means of a wholly intra-normative metaphysically explanatory picture. No metaphysically explanatory relation between discontinuous facts will thus be involved. As I have emphasized, this will not save non-naturalism from all queerness worries. Indeed, since the proposal embraces an irreducibly normative reason-relation, the Mackiean qualms concerning objective prescriptivity will certainly remain. But the proposal does reduce two queerness worries to one.

Acknowledgements For helpful questions and comments, I am grateful to audiences at the Uppsala Higher Seminar in Practical Philosophy and at the Stockholm August Workshop in Philosophy. I am especially grateful to Stina Björkholm, Krister Bykvist, Karin Enflo, Jens Johansson, Jonas Olson, Olle Risberg, Henrik Rydéhn and several anonymous referees.

Funding Open access funding provided by Stockholm University. Research funded by the Swedish Research Council (Project Id: 2019-02828).

Data availability Not applicable.

Code availability Not applicable. 


\section{Declarations}

\section{Conflict of interest None.}

Open Access This article is licensed under a Creative Commons Attribution 4.0 International License, which permits use, sharing, adaptation, distribution and reproduction in any medium or format, as long as you give appropriate credit to the original author(s) and the source, provide a link to the Creative Commons licence, and indicate if changes were made. The images or other third party material in this article are included in the article's Creative Commons licence, unless indicated otherwise in a credit line to the material. If material is not included in the article's Creative Commons licence and your intended use is not permitted by statutory regulation or exceeds the permitted use, you will need to obtain permission directly from the copyright holder. To view a copy of this licence, visit http://creativecommons.org/licenses/by/4.0/.

\section{References}

Bader, R. 2017. The grounding argument against non-reductive moral realism. In Oxford studies in metaethics 12, ed. R. Shafer-Landau, 106-134. Oxford: Oxford University Press. https://doi.org/10.1093/oso/ 9780198805076.003.0005.

Berker, S. 2019. The explanatory ambitions of moral principles. Nô̂s 53(4): 904-936. https://doi.org/10. 1111 /nous. 12246.

Bliss, R., and K. Trogdon. 2016. Metaphysical grounding. In The Stanford encyclopedia of philosophy (Winter 2016 Edition), ed. E.N. Zalta. https://plato.stanford.edu/archives/win2016/entries/grounding/.

Chalmers, D. 1996. The conscious mind: In search of a fundamental theory. New York: Oxford University Press.

Dancy, J. 2006. Nonnaturalism. In The Oxford handbook of ethical theory, ed. D. Copp, 122-145. New York: Oxford University Press. https://doi.org/10.1093/oxfordhb/9780195325911.003.0005.

Dasgupta, S. 2014. The possibility of physicalism. The Journal of Philosophy 111(9/10): 557-592. https:// doi.org/10.5840/jphil20141119/1037.

Enoch, D. 2011. Taking morality seriously: A defense of robust realism. Oxford: Oxford University Press. https://doi.org/10.1093/acprof:oso/9780199579969.001.0001.

Faraci, D. 2017. Hybrid non-naturalism does not meet the supervenience challenge. Journal of Ethics and Social Philosophy 12(3): 312-318. https://doi.org/10.26556/jesp.v12i3.279.

FitzPatrick, W.J. 2008. Robust ethical realism, non-naturalism, and normativity. In Oxford studies in metaethics 3, ed. R. Shafer-Landau, 159-205. Oxford: Oxford University Press.

Fogal, D., and O. Risberg. 2020. The metaphysics of moral explanations. In Oxford studies in metaethics 15, ed. R. Shafer-Landau, 170-194. Oxford: Oxford University Press. https://doi.org/10.1093/oso/97801 98859512.003.0008

Glazier, M. 2016. Laws and the completeness of the fundamental. In Reality making, ed. M. Jago, 11-37. Oxford: Oxford University Press. https://doi.org/10.1093/acprof:oso/9780198755722.003.0002.

Hattiangadi, A. 2018. Moral supervenience. Canadian Journal of Philosophy 48(3/4): 592-615. https://doi. org/10.1080/00455091.2018.1436034.

Huemer, M. 2005. Ethical intuitionism. Basingstoke: Palgrave Macmillan. https://doi.org/10.1057/97802 30597051 .

Jackson, F. 1998. From metaphysics to ethics: A defence of conceptual analysis. Oxford: Clarendon Press. https://doi.org/10.1093/0198250614.001.0001.

Leary, S. 2017. Non-naturalism and normative necessities. In Oxford studies in metaethics 12, ed. R. ShaferLandau, 76-105. Oxford: Oxford University Press. https://doi.org/10.1093/oso/9780198805076.003. 0004.

Mackie, J.L. 1977. Ethics: Inventing right and wrong. Harmondsworth: Penguin Books.

Majors, B. 2005. Moral discourse and descriptive properties. The Philosophical Quarterly 55(220): 475-494. https://doi.org/10.1111/j.0031-8094.2005.00412.x.

McGinn, C. 1989. Can we solve the mind-body problem? Mind 98(391): 349-366. https://doi.org/10.1093/ mind/XCVIII.391.349.

McPherson, T. 2012. Ethical non-naturalism and the metaphysics of supervenience. In Oxford studies in metaethics 7, ed. R. Shafer-Landau, 205-234. Oxford: Oxford University Press. https://doi.org/10.1093/ acprof:oso/9780199653492.003.0007. 
McPherson, T. 2019. Supervenience in ethics. In The Stanford Encyclopedia of Philosophy (Winter 2019 Edition), ed. E. N. Zalta. https://plato.stanford.edu/archives/win2019/entries/supervenience-ethics/.

Olson, J. 2014. Moral error theory: History, critique, defence. Oxford: Oxford University Press. https://doi. org/10.1093/acprof:oso/9780198701934.001.0001.

Parfit, D. 2011. On what matters: Volume two. Oxford: Oxford University Press. https://doi.org/10.1093/ acprof:osobl/9780199572816.001.0001.

Roberts, D. 2018. Why believe in normative supervenience? In Oxford studies in metaethics 13, ed. R. Shafer-Landau, 1-24. Oxford: Oxford University Press. https://doi.org/10.1093/oso/9780198823841. 003.0001 .

Rosen, G. 2010. Metaphysical dependence: Grounding and reduction. In Modality: Metaphysics, logic, and epistemology, ed. R. Hale and A. Hoffman, 109-136. Oxford: Oxford University Press. https://doi.org/ 10.1093/acprof:oso/9780199565818.003.0007.

Rosen, G. 2017. What is a moral law? In Oxford studies in metaethics 12, ed. R. Shafer-Landau, 135-159. Oxford: Oxford University Press. https://doi.org/10.1093/oso/9780198805076.003.0006.

Rydéhn, H. 2019. In virtue of: Determination, dependence, and metaphysically opaque grounding. Uppsala: Department of Philosophy, Uppsala University.

Scanlon, T. 2014. Being realistic about reasons. Oxford: Oxford University Press. https://doi.org/10.1093/ acprof:oso/9780199678488.001.0001.

Schroeder, M. 2007. Slaves of the passions. Oxford: Oxford University Press. https://doi.org/10.1093/acprof: oso/9780199299508.001.0001.

Skarsaune, K.O. 2015. How to be a moral platonist. In Oxford studies in metaethics 10, ed. R. Shafer-Landau, 245-272. Oxford: Oxford University Press. https://doi.org/10.1093/acprof:oso/9780198738695.003. 0010.

Toppinen, T. 2018. Essentially grounded non-naturalism and normative supervenience. Topoi 37(4): 645653. https://doi.org/10.1007/s11245-017-9456-X.

Moberger, V. 2019. The Mackiean supervenience challenge. Ethical Theory and Moral Practice 22(1): 219-236. https://doi.org/10.1007/s10677-019-09987-5.

Moberger, V. 2020. Hume's dictum and metaethics. The Philosophical Quarterly 70(279): 328-349. https://doi.org/10.1093/pq/pqz058.

Publisher's Note Springer Nature remains neutral with regard to jurisdictional claims in published maps and institutional affiliations. 